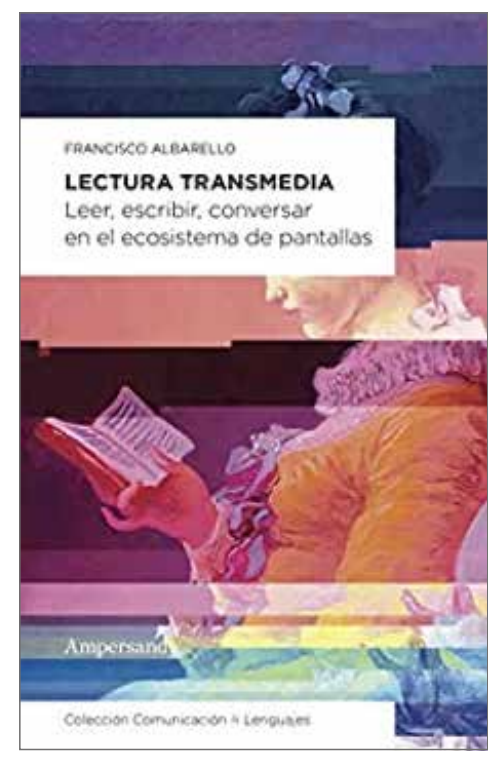

\title{
Lectura Transmedia. Leer, escribir, conversar en el ecosistema de pantallas
}

\author{
Albarello, $\mathbf{F}$.
}

Ampersand, Ciudad Autónoma de Buenos Aires, 2019. 224 pp.

Por: Maltz, H. ${ }^{1}$

Recibido: 17-08-2020 - Aceptado: 20-01-2021

https://doi.org/10.26441/RC20.1-2021-R2

¿Qué significa leer en el siglo XXI? Tal podría ser la pregunta de investigación que se posa Francisco Albarello, autor de Lectura Transmedia. Leer, escribir, conversar en el ecosistema de pantallas. Hallamos una primera respuesta, apta para ansiosos extremos, en el mismo título del libro (mérito que pocos tienen la pericia de lograr): estamos ante una coyuntura histórica en que se manifiesta el fenómeno de la lectura transmedia, que implica, entre varias dimensiones, un conjunto de habilidades cognitivas y operativas que no se restringen a lo que usualmente el sentido común identifica como la única forma de lectura "válida", es decir, aquella que tiene lugar de manera lineal, inmersiva y con textos en soporte impreso. En el subtítulo, observamos otras dos incipientes respuestas que, a lo largo del itinerario argumentativo, resultan ampliadas: por un lado, la inevitabilidad de vivir en un contexto signado por un ecosistema de pantallas, en que se realizan prácticas de lectura multilineales y multisecuenciales, en distintos soportes e interfaces; por otro, los tres verbos del subtítulo del libro, colocados en infinitivo, anticipan una cuestión que el autor destaca como uno de los rasgos distintivos de la lectura transmedia, en que las acciones de lectura y escritura de una persona están, como nunca antes, entrelazadas de manera casi simultánea con las actividades de lectura y escritura de otros sujetos -fenómeno cuyo cenit observamos en la práctica del chat-.

Podemos aproximarnos a los nueve capítulos que componen el libro como sub-argumentos de uno más grande y englobante -en torno a la complejidad y la especificidad del fenómeno de la lectura en el siglo XXI-, aunque, asimismo, podríamos leerlos como ensayos con relativa independencia entre sí (y tiene sentido que un libro impreso, que trata sobre la ampliación de la lectura por fuera del paradigma de la lectura intensiva y lineal, pueda proponer esta variante de acercamiento no lineal, aunque un lector conservador y porfiado, como el de esta reseña, insista en consumir el texto de manera continuada y concentrada). Con una inscripción disciplinaria en los estudios de comunicación $\mathrm{y}$, en particular, en una perspectiva evolucionista sobre la historia de los medios, el recorrido de los capítulos nos conduce a través de los siguientes temas: una contextualización sobre la ecología de las pantallas en que vivimos; una recapitulación sobre la historia de la lectura; una descripción sobre una diversidad de consumos que efectuamos en múltiples plataformas y dispositivos; una especificación del concepto de interfaz, especialmente en la variante dada por el software; una historización

\footnotetext{
${ }^{1}$ Hernán Maltz es Doctor en Literatura y Licenciado en Sociología por la Universidad de Buenos Aires. Se desempeña como becario posdoctoral del Consejo Nacional de Investigaciones Científicas y Técnicas y docente universitario. Trabaja en proyectos de investigación sobre narrativa policial argentina y sociologías de la literatura. hermaltz@gmail.com, https://orcid.org/0000-0003-2274-1873
} 
sobre el hipertexto, desde mediados del siglo XX hasta la actualidad; una digresión sobre la versatilidad de nuestras capacidades neuronales; una reflexión sobre el chat, que emerge como un género vital del ecosistema de pantallas, en que las actividades de lectura y escritura se alternan con una inmediatez inédita; y, no por último, una consideración sobre una serie de desafíos que conlleva la alfabetización transmedia -proceso que incluye una faceta educativa en vinculación con las instituciones tradicionales de enseñanza, aunque no se reduzca a ella-, además de algunos avances de una investigación, en estado exploratorio, sobre las formas en que los jóvenes universitarios estudian con múltiples medios y dispositivos.

A lo largo del itinerario que propone Albarello, nos encontramos con una amplia variedad de modalidades de lectura: lineal, no lineal, multilineal, inmersiva, concentrada, extensiva, superficial, oralizada, silenciosa, solitaria, móvil, intersticial, ubicua, colectiva, colaborativa, conectiva, secuencial, no secuencial, multisecuencial, selectiva, fragmentada, digital, etcétera. Entre ellas, la que adquiere mayor relevancia -y que aglomera varias de las modalidades anteriores- es la ya referida lectura transmedia: "un tipo de lectura inclusiva, multimodal, diversa, de todo tipo de textos -escritos, visuales, sonoros, lúdicos- y de soportes, que a su vez se mezcla e hibrida con las prácticas de producción o prosumo del lector" (166). Así, esta modalidad emergente de lectura supone, entre otros aspectos, la multiplicación de las pantallas en la vida cotidiana, que resulta ya inconcebible sin la presencia de smartphones, tablets, e-readers y laptops -dispositivos cuyos usos tienden a converger no solo entre ellos, sino con otros medios precedentes, como la televisión o los libros en formato impreso-.

Ahora bien, en un contexto nacional (como el argentino) caracterizado por desigualdades y pobrezas de grandes segmentos poblacionales, cabe preguntarse si la inevitabilidad de las pantallas en nuestras vidas cotidianas debiera asumirse como un punto de partida o como otro factor a ser problematizado en la investigación en ciencias sociales. Desde luego, Albarello no ignora esta cuestión, aunque, en todo caso, tendríamos derecho en reclamar una mayor atención al respecto, ya que apenas observamos una exigua mención a la brecha digital, que "separa a quienes tienen de quienes no tienen acceso a computadoras conectadas a Internet" (175). Ante este comentario, la preocupación del autor pasa por advertirnos sobre una serie de capacidades necesarias para la alfabetización transmedia, proceso que precisa de la posesión de dispositivos como condición necesaria, pero no suficiente: "la brecha digital no se produce solamente al nivel de acceso a los aparatos conectados a Internet, sino también a nivel cognitivo" (176). A partir de este giro argumentativo, Albarello se ocupa de analizar las capacidades y habilidades necesarias para el adiestramiento de los sujetos en el ecosistema de pantallas. Aquí, sin embargo, nos permitimos insistir en la importancia de dar mayor lugar a los fenómenos de desigualdad y pobreza, pues la adquisición de smartphones, tablets, e-readers y laptops se torna dificultosa $-\mathrm{y}$, en contextos devaluatorios de la moneda nacional, acaso imposible-, incluso para sectores medios de la población.

Si bien el fenómeno de la lectura transmedia -en el marco de una ecología mediática dominada por pantallas- dista de implicar una expansión democrática de las prácticas de lectura, sin duda nos situamos ante la emergencia de una modalidad que pone en jaque la testarudez de ciertas visiones que insisten, erróneamente, en concebir la lectura concentrada de publicaciones en soporte impreso como la única opción legítima y "verdadera”. De hecho, así como este tipo de actividad cognitiva supuso un aprendizaje y "una interiorización de una tecnología artificial como la escritura" (186), la lectura transmedia nos coloca ante un desafío más amplio en torno a los procesos de generación de conocimiento; se trata de "desnaturalizar lo que se ha naturalizado, para volverlo a naturalizar pero a una nueva escala, donde desarrollemos nuevos tipos de inteligencia que asuman la interrupción, la simultaneidad, la fugacidad y la superficialidad como componentes -y no como meros distractoresde la tarea del conocimiento" (186). 
Por medio de una exposición desplegada en distintos niveles de análisis y escrita en un lenguaje diáfano y accesible, Albarello nos convence de que "leer ya no es lo que era" (19), a través de una serie de reflexiones que poseen un indudable éxito en el objetivo que se propone al comienzo: "ofrecer un marco conceptual para investigar, describir y teorizar acerca de los modos en los que leemos o consumimos textos -en sus múltiples formas- en la actualidad" (19). De esta forma, como todo buen cientista social, nos sensibiliza sobre la complejidad de una actividad a la que los sentidos comunes tienden a reducir en sus significados y alcances. 